\title{
Open innovation in IT brands in Cluj-Napoca
}

\author{
Ligia Maria $\mathrm{Nan}^{1,2}{ }^{*}$, Roxana Lavinia Păcurariu ${ }^{1}$ and Laura Bacali ${ }^{1,2}$ \\ ${ }^{1}$ Faculty of Machine Building, Technical University of Cluj-Napoca, 400641 Cluj-Napoca, Romania \\ ${ }^{2}$ Center for Innovation and Organizational Sustainability, Cluj-Napoca 400609, Romania
}

\begin{abstract}
This article presents the concept of open innovation in IT brands, an industry that is always evolving. We will present the results of a preliminary study regarding the benefits of open innovation on ClujNapoca IT brands, the evolution of the number of employees from large companies in the industry and the future direction of research. The sample of the study contains 37 firms selected from a total of 1,490 companies registered in Cluj-Napoca.
\end{abstract}

\section{Introduction}

This study aims to analyze how the concept of how open innovation helps and develops the IT industry. Due to the accelerated growth and development of this industry, traditional innovation is no longer enough to withstand on the market, therefore the firms have to approach and implement open innovation. The study is part of early-stage research in the city of Cluj-Napoca, regarding how the online communication channel is being used, specifically social networking sites. It offers future prospects for research and aims to enrich the existing literature. The concept of open innovation can be interesting for organizations and it encourages the development and improvement of websites to obtain a better firm image. In the first part of the study, we will present the theoretical part of the concept of open innovation for its importance in branding and in the IT industry. Then we will present the way the study was carried out, which was possible by analyzing the content of the chosen companies' websites. To investigate how IT firms present the concept of open innovation on their websites, we will try to answer to the following questions in defining the research: How noticeable is the communication of the concept of open innovation on specific firms' websites? and To what extent do they communicate this concept? In the last part, we will present the findings and conclusions of this study, as well as the future directions of research. The growing interest for open innovation indicates the fact that this is becoming a necessity for firms, in order to be able to grow, to be active in innovation and to remain competitive. The concept of open innovation began to be promoted by Chesbrough, thus he created a new paradigm, which is accepted worldwide, being implemented in companies and studied in schools. The concept of open innovation encourages companies and organizations to use both external and internal ideas for innovation and to share their own ideas with other firms wanting to grow [1].

${ }^{*}$ Corresponding author: ligianan@yahoo.com 


\section{The concept of open innovation}

The concept of open innovation has been greeted with great receptivity from the beginning and has been adopted in a multitude of areas. It has brought major changes to the innovation process, it has led organizations to be more open and it has managed to create new opportunities and to demolish barriers [2]. In other words, open innovation supports the collaboration between different people, R\&D institutions, startups, SMEs, large companies, universities and other organizations, aiming at innovation and sharing both risks and gains [3,4]. The main benefits of implementing the concept of open innovation in a firm are [5]: lower-cost profitability for R\&D activities, customer involvement from the early stages of development, competitive advantage and improved productivity of the R\&D process. During the implementation process, risks and challenges automatically occur. The main disadvantages identified are [6]: the likelihood of disclosing too much information that is not intended for disclosure, potential issues related to intellectual property ownership and the likelihood of losing the competitive advantage due to the disclosure of too much information. Open innovation brings benefits and creates opportunities for entrepreneurs and small companies. It can help them develop and introduce new brands on the market. This can be accomplished by outsourcing the design, involving the end user in all stages of the development process [7]. The benefits of engaging in open innovation have impacts on the long term process. We can identify the following benefits: abundant ideas and knowledge, opportunities to create value, the improvement of reputation, building relationships, discovering talents that can be potential innovators or employees and having a shared customer base [8]. Herzog [9] identifies the following as the most common forms of open innovation: internal research, patenting, joint $\mathrm{R} \& \mathrm{D}$ agreements, innovation competitions, joint ventures and acquisitions. The crowdsourcing is considered to be a form of open innovation by which consumers become producers. It plays a major role in the process of creating, organizing and sharing knowledge, making it easy to use online platforms and social networks $[10,11]$. The process of open innovation contains a phase of exploration and knowledge creation, both internally and externally $[12,13,14]$, a phase of knowledge retention [15] and a phase of knowledge transfer [16]. The internal exploration of knowledge represents the generation and development of new ideas within the company, and the external one is about bringing ideas from outside the firm. The knowledge retention phase is necessary to keep the knowledge and relationships established for a long time. The final phase is all about applying the ideas of internal innovations, as well as sharing them with the company's external environment [17]. The influence of the brand on open innovation can be seen in a study by Füller and Matzler [18]. Through this study, they wanted to see whether the brand is one of the factors that influence consumers in participating in open innovation projects of a company and if consumers have the desire to share their ideas and knowledge with the firm [19]. The findings show that the willingness to participate in open innovation projects is heavily influenced by the consumer's capacity, such as motivation, skills and creativeness. Then, the consumer can also be influenced by the trust he has in the brand. Nørskov, Antorini and Jensenh [20], show that partner and consumer attitude towards the brand determines their involvement in the firm's projects.

Brand loyalty influences the desire to share ideas and strengthens collaboration on open innovation. In order to maximize the involvement of all stakeholders, the firm must be the one to take the first step and to create communities in which innovation is encouraged [21]. The companies have to invest in relationships, to share their innovations and to create opportunities for interaction on open innovation activities. In order to involve easily the stakeholders of a firm brand in open innovation activities, they can turn to social networks. It is important and beneficial for brands to interact with all stakeholders, users, consumers and suppliers. They want to interact with a brand they can trust and identify with. By 
maintaining relationships, brands create experiences, which can be both useful and entertaining, bringing satisfaction to both. In this way, the firms gain brand support, which improves brand identity, brand positioning and brand reputation [22]. Social networks have a major influence in the open innovation process, because through them communication costs are reduced and they bring multiple possibilities for interaction and active participation in the user innovation process $[23,24]$. In the IT industry, the concern for open innovation began with the open source trend. Today, the largest companies place the concept of open innovation at strategic level. Open innovation process starts from simple outsourcing transactions in order to reduce overload, costs and risks [25]. We can identify several factors that make it difficult to apply open innovation to the IT industry. These factors relate to: privacy, human resources, brand, image, resources, costs, management, culture, organization, market, partnerships and technology [26]. In recent years, an improved concept was developed, called open innovation 2.0. The essence of the improvements is due to multidisciplinary experiments. This new paradigm is based on the creation of common values and common vision, integrated collaboration, accelerated collaborative research, co-creation of shared value, virtual innovation ecosystems and coexperimentation and user involvement $[27,28,29]$.

\section{Methodology}

To analyze the existence of the concept of open innovation in the IT industry, we have chosen a database provided by the Chamber of Commerce and Industry of Cluj-Napoca. This database contains 1490 IT firms from Cluj-Napoca, registered under the CAEN codes 62 and 63 . We selected for this study only those firms that meet the conditions of being a large company: firms with more than 50 employees in 2016 and a turnover of more than 500,000 euro (equivalent to 2,225,000 RON) in 2016. Following this selection, 37 firms remain to analyze. In this analysis, we decided to use only these 37 large companies and to research their websites to find out information about open innovation. We searched for any information, involvement or projects linked to the concept of open innovation.

Being a growing industry, we wanted to observe the evolution of the number of employees in the large companies in Cluj-Napoca. We have made a graph to show the evolution of the number of employees from the 37 large IT firms in Cluj-Napoca in the last five years.

This study is exploratory and descriptive. The study includes 37 large companies; out of a total of 1,490 IT firms in Cluj-Napoca.

\section{Preliminary results}

\subsection{The analysis of the concept of open innovation within the IT brands in Cluj-Napoca}

The study implies analyzing the websites of the largest companies in Cluj-Napoca in order to see which of them have submitted information about open innovation. The analysis of the relevant websites was carried out, in the period between 05 and 30 June 2017. From a total of 1,490 companies, only 247 have a Facebook social network page.

The analysis showed that out of 37 firms used in our study, only three had an open innovation section and these were subject to further analysis. These three firms $(8 \%)$ literally specify the term open innovation and they have initiated projects and programs that encourage the development of the concept. These are: NTT Data, NEUSOFT and ALTRAN. As for the other firms, they do not mention this concept directly. 
For 21 companies (57\%) we can assume that they have information that indirectly refers to this concept, even if the term is not literally specified on their websites. We can assume this from the various activities that we are undertaking to develop into everything related to open innovation.

We recall some of these activities: partnerships with the education system and other areas different from the main field of activity, startup collaborations, participation in conferences on open innovation topics, development of professional platforms and forums for users, offering open source solutions and infrastructure. Then, there are the remaining 13 firms (35\%), who have no information about this concept. The findings of the analysis are summarized in Table 1. NTT Data has a separate website dedicated to the open innovation concept, detailing the three ways it addresses and implements the concept of open innovation. These are: open innovation forum called "From the Port of Toyosu", open innovation business contest, open innovation assistance program called DCAP (Digital Corporate Acceleration Program).

Table 1. Research results.

\begin{tabular}{|l|l|l|}
\hline & Number of firms & $\%$ \\
\hline Sample size & 1490 & \\
\hline Firms registered on Facebook & 247 & $16,6 \%$ \\
\hline Firms with over 50 employees & 37 & $2,5 \%$ \\
\hline Firms with a turnover over 2,225,000 RON & 37 & $2,5 \%$ \\
\hline Characteristics of open innovation concept & 3 & $8 \%$ \\
\hline Mentioned directly & 21 & $57 \%$ \\
\hline Mentioned indirectly & 13 & $35 \%$ \\
\hline Not at all mentioned &
\end{tabular}

NEUSOFT focuses on sustainable improvement through open innovation. The mission statement of the company declares its commitment to alliances and open innovation. ALTRAN organizes the Open Innovation Conference in Italy and it has opened the Open Innovation Institute in France. Innovative Product Development is the way the company applies the concept of open innovation, thereby encouraging outsourcing of the industrialization, production or development processes.

\subsection{The evolution of the number of employees in the IT industry in the last five years in the largest companies in Cluj-Napoca}

Softvision is the largest company in 2016, based on the number of employees, having 1,160 employees, with 464 more than in 2012, as can be seen from Figure 1. NTT Data is followed by 646 employees, with 406 employees in addition to 2012, and in the third place is Fortech, having 550 employees, with an increase of 311 employees. Arobs Transilvania Software has 457 employees, with 180 employees in addition to 2012. Evozon Systems has 437 employees, with 290 more than in 2012. The largest evolution regarding the number of employees can be seen in seven companies (19\%), with an increase of more than 200 employees in the last five years. These companies are: Sofvision, NTT Data, Fortech, Evozon Systems, Access IT Systems, Betfair Romania Development and 3Pillar Global. Six companies (16\%) registered an increase in the number of employees between 100 and 200 and the remaining 22 companies $(60 \%)$ registered an increase in the number of employees between 1 and 100. Only two companies (5\%) experienced a significant decline in the number of employees, Neusoft EDC, which dropped by 104 employees and Active Power Solutions dropped by 50 employees. Over $40 \%$ companies have doubled their workforce over these five years. 


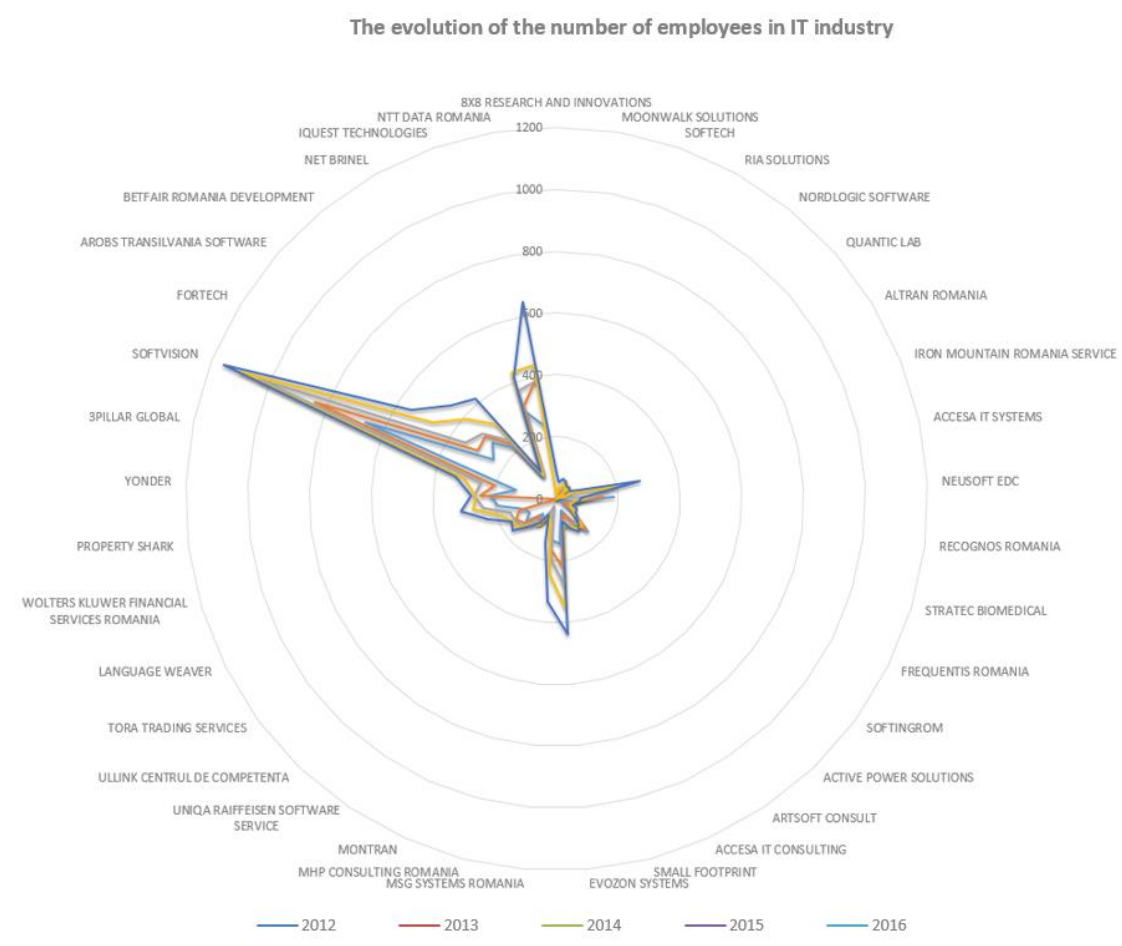

Fig. 1. The evolution of the number of employees in IT industry.

\section{Conclusions and following research direction}

The IT industry is always concerned and focused on innovation. It is open to new ideas and always applies the latest concepts. The findings show that the number of large IT companies in Cluj-Napoca with information about open innovation on their websites is very low. Companies that specifically mentioned the concept of open innovation have an orientation for it and have initiated projects and programs to promote and develop the concept. Most of the companies did not specifically mention the term open innovation, but they began to take a few steps towards assimilation, by attending conferences on open innovation topics, or using some of the forms of open innovation. The recognition of the concept of open innovation is largely influenced by the reputation of the brand that promotes the concept. The IT industry has a great impact on the concept by the fact that this industry is founded on innovation. In the future, we will expand the research by studying the role of social networks in branding and the extent to which companies are open to the new concepts of open innovation. We will deepen our understanding on the influence and the impact that social networks have on the branding concept in the IT industry.

"This work was undertaken through the Partnerships in Priority Domains: Programme-PN II, developed with the support of MEN-UEFISCDI, Project no.337/2014- UNIINOI".

\section{References}

1. H. Chesbrough, Open Innovation: The New Imperative for Creating And Profiting from Technology, Harvard Business School Press, Boston, Massachusetts, (2003) 
2. J. West, A. Salter, W. Vanhaverbeke, H. Chesbrough, Research Policy 43 (5), 805 (2014)

3. K. Șimșek, N. Yildirim, Procedia - Social and Behavioral Sciences, 235 (24), 719 (2016)

4. O. Granstrand, The economics of IP in the context of a shifting innovation paradigm, Innovation Report 2011: Shifting Innovation Paradigms and the Role of Intellectual Property. WIPO, Geneva (2011)

5. S.J. Marais, C.S.L. Schutte, The Development of Open Innovation Models to Assist the Innovation Process, University of Stellenbosch, South Africa (2010)

6. P. Trott, D. Hartmann, International Journal of Innovation Management, 13 (4), 715 (2009)

7. K. Hamid, Int. J. Entrepreneurship and Small Business, 7 (4), 457 (2009)

8. H. Chesbrough, The Era of Open Innovation, MIT Sloan Management Review, 44 (2003)

9. P. Herzog, Open and closed innovation: different cultures for different strategies, Gabler Verlag, (2008)

10. R. B. Bauer, T. Gegenhuber, Crowdsourcing: Global search and the twisted roles of consumers and producers, Institute of Organization and Global Management Studies, Johannes Kepler University Linz, 22 (5), 661 (2015)

11. M.N. Wexler, Reconfiguring the sociology of the crowd: exploring crowdsourcing, International Journal of Sociology and Social Policy, 31, (2011)

12. K.G. Smith, C.J. Collins, K.D. Clark, Academy of Management Journal, 48 (2), 346 (2005)

13. P.J. Lane, B.R. Koka, S. Pathak, Academy of Management Review, 31 (4), 833 (2006)

14. B. Cassiman, R. Veugelers, Management Science, 52, 68 (2006)

15. L. Argote, B. McEvily, R. Reagans, Management Science, 49, 571 (2003)

16. W. C. Bogner, P. Bansal, Journal of Management Studies, 44 (1), 165 (2007)

17. U. Lichtenthaler, E. Lichtenthaler, Journal of Management Studies, 46, (2009)

18. J. Füller, K. Matzler, M. Hoppe, The Journal of Product Innovation Management, 25, (2008)

19. J. Füller, Advances in Consumer Research Volume, 33, (2006)

20. S. Nørskov, Y. M. Antorini, M. B. Jensen, International Journal of Innovation Management, 20, (2016)

21. M. R. Martínez-Torres, Expert Systems with Applications, 7, (2013)

22. J. Prell, R. Schleich, Social Open Innovation in Online Brand Communities with Particular Regard to the Social Exchange Theory and Brand Management, Lund University, School of Economics and Management, (2015)

23. J. Bughin, A. Hung Byers, M. Chui, How social technologies are extending the organization, McKinsey Quarterly, (2011)

24. E. S. Lakatos, L. Bacali, O. B. Bercea, C. M. Muresan, A. Moldovan, The benefits of IT tools in innovation process for SME sustainability, In International Conference in Advances in Management, Economics and Social Sciences, (2015)

25. O. Gassman, E. Enkel, H. Chesbrough, The future of open innovation, R\&D Management, 40, (2010)

26. W. Krause, C. Schutte, N. du Preez, Open Innovation in South African Small and Medium-Sized Enterprises, CIE42 Proceedings, Cape Town, South Africa, 26, (2012)

27. M. Curley, B. Salmelin, Open innovation 2.0: A new paradigm, Cambridge, MA: Academic Press, (2013)

28. M. Curley, Twelve principles for open innovation 2.0, Nature, (2016)

29. E, Motoiu, O. A. Pavel, E. S. Lakatos, Review of Applied Socio-Economic Research, 11, (2016) 